\title{
A PANDEMIA DO COVID-19 E SUAS IMPLICAÇÕES PARA A LOGÍSTICA DE TRANSPORTE BRASILEIRA
}

Ariadne Guerra Souza (Universidade Federal de Campina Grande) ariadne.guerra@hotmail.com

\author{
Gabriella Luiza Pereira de Sá (Instituto Federal do Sertão Pernambucano) \\ gabriella.sa@ifsertao-pe.edu.br \\ Hellen Leite Neves (Universidade Federal de Campina Grande) \\ hellennves@icloud.com \\ Mariana Paiva Brito (Universidade Federal de Campina Grande) \\ marianapaivabrito@gmail.com \\ Vanessa Nóbrega da Silva (Instituto Federal do Sertão Pernambucano) \\ vanessa.nobrega@ifsertao-pe.edu.br
}

\section{Resumo:}

Um bom planejamento logístico é essencial para o funcionamento satisfatório das organizações, tendo em vista a busca incessante por vantagens competitivas. Nesse sentido, a logística de transporte se faz primordial para o alcance dessas e para que se tenha consumidores atendidos e satisfeitos com o serviço que lhes é oferecido. a Logística de Transporte se faz primordial. No ano de 2020, o Brasil vem enfrentando uma pandemia do COVID-19 e com isso, são várias as dificuldades enfrentadas pelo país e pelos setores relacionados à logística. Diante desse cenário, o artigo tem como objetivo analisar quais foram as implicações da pandemia na logística de transporte. Para isso, foi realizada uma revisão bibliográfica sobre o tema, seguido de uma pesquisa explicativa a fim de descobrir como a logística de transporte está sendo afetada. Como resultado, foram encontrados alguns gargalos, advindos da pandemia, como o aumento do lead time, diminuição da produtividade, perda da performance de entrega, aumento dos custos logísticos e queda nos níveis de serviços.

Palavras-chave: Pandemia; Covid-19; Logística de transporte.

\section{INTRODUÇÃO}

A logística foi uma atividade que passou a ter grande importância no contexto da Segunda Guerra Mundial, período em que a demanda de produtos era cada vez mais alta. Inicialmente, possuía maior enfoque no processo de fabricação dos produtos, desde a obtenção de matériasprimas até os produtos finalizados. Com o passar do tempo, o pós-venda passou a ganhar ganhar 
relevância também, visto que era uma parte essencial para o cliente fazer maior proveito e agregar valor a sua compra (NÓBREGA, 2010).

A atividade logística de transporte está inclusa no pós-venda e se faz extremamente necessária, sendo responsável por grande parte dos custos nas organizações. Porém é também um fator que permite garantir uma melhor posição no mercado competitivo e faz com que as empresas tenham menor tempo de resposta aos clientes, de forma que estes tenham as mercadorias dentro do prazo desejado (MOREIRA, 2019).

No ano de 2020, devido à pandemia do novo coronavírus (SARS-CoV-2), a logística de transporte torna-se ainda mais necessária, uma vez que, a demanda por suprimentos médicos e de subsistência aumentou, atrelada ao fato de que foram necessárias adaptações e adoção de restrições em relação a redução de contato, distanciamento social e higienização dos produtos, dentre outros. Nesse contexto, o presente trabalho tem o objetivo de mostrar como a pandemia acarretou implicações significativas na logística de transporte brasileira.

\section{REFERENCIAL TEÓRICO}

\subsection{PANDEMIA DO COVID-19}

O Ministério da Saúde afirma que "a COVID-19 é uma doença causada pelo coronavírus SARSCoV-2, que apresenta um quadro clínico que varia de infecções assintomáticas a quadros respiratórios graves" (BRASIL, 2020). Com o primeiro caso confirmado no Brasil em 26 de fevereiro de 2020 no estado de São Paulo, o país viu crescer o número de infectados em um intervalo de pouco mais de 2 meses, conforme ilustra a Tabela 1.

Tabela 1: Cenário da pandemia no Brasil entre 26 de fevereiro e 20 de maio

\begin{tabular}{|c|c|}
\hline Casos Brasil & $\begin{array}{c}\text { Casos novos de COVID-19 por dados de } \\
\text { notificação }\end{array}$ \\
\hline 26 fevereiro & 0 \\
\hline 26 março & 482 \\
\hline 26 abril & 3.235 \\
\hline 17 maio & 7.938 \\
\hline 20 maio & 19.951 \\
\hline
\end{tabular}

Fonte: Adaptado de https://covid.saude.gov.br/ (2020)

De acordo com a Tabela 1, houve um crescente aumento do número de casos e como consequência disso, diversos setores sofreram alterações, a exemplo destes: saúde, turismo, varejo, aviação, alimentação, dentre outros. Nesse ínterim, a logística também sofre os impactos da pandemia e dentre os setores mais afetados, destaca-se o setor de logística de transporte. Em relação a este último, reflexos já começam a ser percebidos devido à necessidade de isolamento como por exemplo dificuldades produtivas, de acesso e consequentemente as dificuldades 
encontradas no setor de transporte, dado que este setor representa uma atividade essencial para a sociedade.

\subsection{LOGÍSTICA DE TRANSPORTE}

A disposição de insumos tangíveis ou intangíveis aos consumidores, atendendo suas necessidades de consumo de tempo, valor e qualidade requerida são atividades que incluem planejamento, armazenagem e transporte (BALLOU, 2001). Tida como uma atividade primária da logística, o transporte consiste na movimentação de mercadorias tanto dentro da empresa como fora dela e dessa forma sendo um agregador de valor geográfico (PAURA, 2012).

Nesse contexto, a produção de bens e serviços são oportunizados como uma aproximação entre as pessoas e empresas, mas para que isso seja possível é necessário que a logística de transporte seja presente entre essas duas pontas: consumidor e fornecedor. Guereschi (2012) afirma que a logística de transporte desempenha importante papel nessa integração da sociedade com o acesso aos produtos devido ao rompimento dos monopólios provocados pelas barreiras ocasionadas pelo isolamento geográfico, o que reflete em possíveis vantagens competitivas em custos. $\mathrm{O}$ autor pontua ainda que o gerenciamento dos custos, planejamentos, tecnologias da informação, estratégias, dentre outros, são elementos que auxiliam os empreendimentos a conseguirem suprir as necessidades do mercado de transporte, bem como a logística a ele associado.

Diante do exposto, o transporte possui uma relevante função na logística, uma vez que, é através dele que a cadeia logística ocorre de forma apropriada, permitindo assim que toda as etapas da cadeia de suprimentos sejam cumpridas e dessa forma, os clientes tenham as suas necessidades supridas. Devido ao fato das suas funções estarem relacionadas às dimensões de tempo e utilidade de lugar, é fundamental uma atenção para o planejamento desta atividade, pois sem este estar adequado, os custos da cadeia serão encarecidos e dessa forma a relação entre consumidor e fornecedor será enfraquecida, degradando o potencial competitivo da organização e não atendendo o objetivo da logística no que se diz respeito ao menor custo possível (PORTOGENTE, 2016).

No Brasil, as atividades econômicas estão diretamente relacionadas à logística de transporte, sendo assim, o transporte é considerado uma das bases fundamentais que possibilitam o desenvolvimento do país e dessa forma, é necessário que o país possua um sistema desenvolvido e eficiente para alcançar o crescimento. Nessa perspectiva, o crescimento do sistemas de transporte é importante pois é através dele que o PIB do país aumentará e como consequência, o desenvolvimento será alcançado (CNT, 2018).

Pode-se perceber essa importância no atual cenário de pandemia, através dos dados fornecidos pela Confederação Nacional do Transporte em 2020, mostram que desde o ano de 2018, até o 
primeiro trimestre de 2020 ocorreu uma queda no setor do transporte, gerando assim grande perda no PIB total do país, conforme ilustra a Figura 1 :

Figura 1- Gráfico do PIB. Taxa trimestre contra trimestre imediatamente anterior

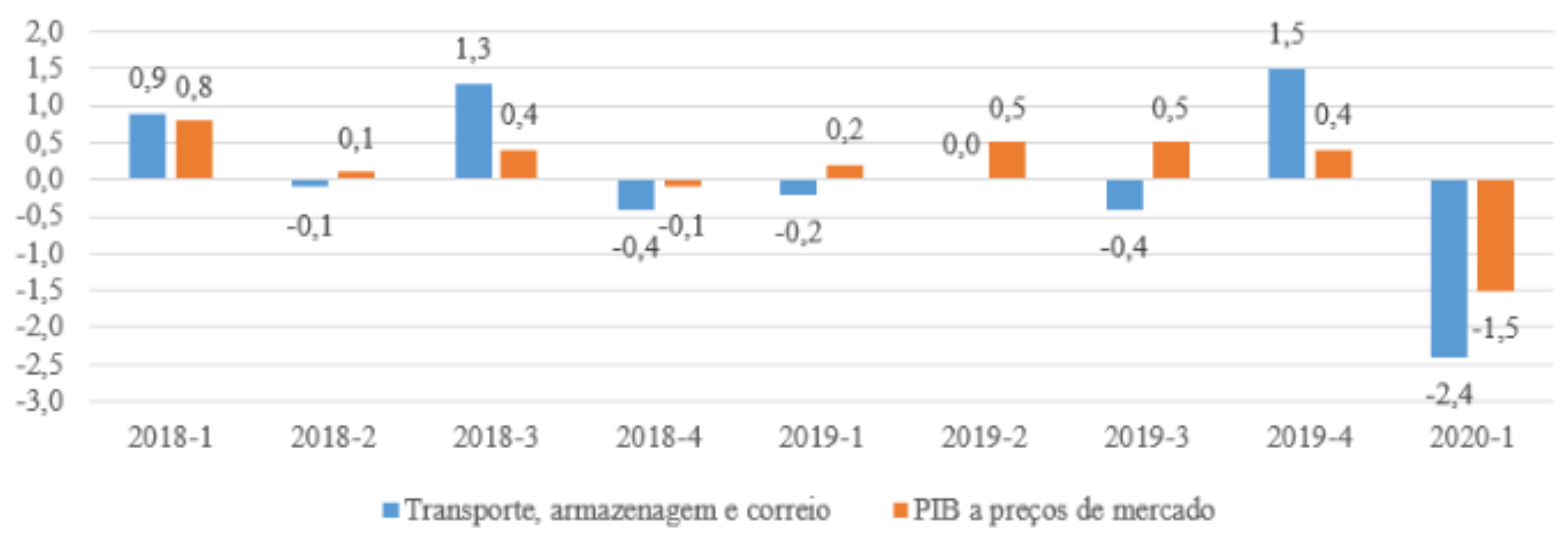

Fonte: Elaborado pelo CNT com dados do IBGE (2020).

Na figura 1, o eixo x corresponde aos trimestres e o eixo y consta os valores percentuais. As barras azuis representam as taxas de crescimento ou decrescimento dos setores de transporte, armazenagem e correio e as barras laranja representam o PIB a preços de mercado. De acordo com a imagem, pode-se perceber que em todos os trimestres que o sistema de transporte decaiu, o PIB foi fortemente afetado. Além disso, o primeiro trimestre de 2020 foi o que o setor de transportes possuiu a maior queda, apresentando uma retração de $2,4 \%$ e em conjunto a ele, o PIB reduziu em $1,5 \%$.

\section{METODOLOGIA}

A pesquisa bibliográfica possui um fator relevante para os demais tipos de pesquisas existentes, sendo elemento balizador para que haja o conhecimento necessário para que um estudo possa ser desenvolvido. Logo, com o objetivo de dominar determinado conhecimento/informação é necessário que haja a compreensão do objeto de estudo e para isso há bibliografias disponíveis que podem contribuir com o aprofundamento da leitura, KÖCHE (2016). Andrade (2017) pontua que é necessário encontrar as razões fundamentais que levam aos registros, análises e interpretações da pesquisa, para então poder haver uma explicação dos fenômenos observados, caracterizando-a assim, como pesquisa explicativa.

Nesse sentido, para realizar uma investigação sobre os impactos causados à logística de transporte relacionadas ao novo coronavírus (SARS-CoV-2), foi realizada inicialmente uma revisão bibliográfica, com levantamentos de informações sobre a logística de transporte e a pandemia do COVID-19 e seu impacto na logística brasileira. A partir disso, buscou-se realizar uma pesquisa explicativa, com o intuito de compreender como a pandemia está interferindo na logística de transporte. Dessa maneira, foram realizadas pesquisas que discorreram sobre os 
efeitos da pandemia nesse setor, sendo portanto levantadas informações através de vídeos de gestores da área de transporte. e por ser um tema atual, não há muitos trabalhos acadêmicos na área, utilizou-se também de sites para o levantamento de dados e assim obter um direcionamento melhor para explanar sobre o objetivo do estudo. Após a pesquisa e levantamento de dados, elaborou-se o artigo.

\section{RESULTADOS E DISCUSSÕES}

De repente a rotina da população é transformada devido às necessidades de mudanças comportamentais, dos distanciamentos que ora se fazem necessários, dos fechamentos dos comércios, da inexistência de vacina comprovadamente eficaz e de outras informações que lotam os noticiários cotidianamente, há a preocupação de como a logística de transportes se portará em meio a pandemia e após ela, decorrente do crescente volume de informações e exigências de adaptação ao novo cenário.

O cenário pandêmico traz uma preocupação com a saúde e a economia, e consequentemente com a logística de transporte, visto que esta é imprescindível para o atendimento de solicitações tanto de suprimentos médicos quanto aos de subsistência. Assim, todos os setores da economia necessitam se adaptar e/ou reinventar para não perderem espaço no mercado consumidor, tendo que buscar urgentemente estratégias que reduzam ou mitiguem os problemas que estão ocorrendo e que ocorrerão, principalmente os que se dizem respeito a logística de transporte.

Diante dessa perspectiva, o Ministro da Infraestrutura Tarcísio Freitas, afirmou em entrevista fornecida em coletiva de imprensa do Palácio do Planalto em 30/03/2020 que "Nós temos medidas para garantir a proteção dos portuários e a continuidade dos serviços. No que diz respeitos às rodovias federais, tivemos um contato muito bom com os secretários de transporte dos estados. Todos os decretos que precisavam de ajustes foram revistos. Então, todas as atividades de suporte ao transporte estão liberadas", o ministro pontuou ainda que está havendo o abastecimento dos insumos e as estruturas de suporte estão funcionando (BRASIL, 2020).

Com base nas informações citadas anteriormente, observa-se também a importância do transporte para que as atividades não sejam paralisadas, sendo necessária uma adaptação às novas estruturas de mercado relacionadas a esta área da logística. A despeito disso, o IBGE divulgou que houve uma queda de $9 \%$ no setor de transporte no mês de março, sendo o segundo maior índice, tendo o primeiro e maior índice $(9,5 \%)$ relacionado a greve dos caminhoneiros ocorrido em maio de 2018. Segundo a Confederação Nacional de Transportes (CNT), dentre os modais que sofreram retração destacam-se, de acordo com a Tabela 2: 


\begin{tabular}{|c|c|}
\hline Modais & \% Retração \\
\hline Aéreo & 27,5 \\
\hline Terrestre & 10,6 \\
\hline Aquaviário & estável \\
\hline
\end{tabular}

Fonte: Adaptado de CNT (2020)

Observa-se que o modal que mais teve retração, foi o aéreo, seguido do terrestre e tendo o aquaviário ficado sem oscilações.

Ainda nessa perspectiva, a CNT realizou uma pesquisa no mês de abril de 2020, dividindo em duas partes: na primeira, observou sobre retração das empresas do setor de transporte e a segunda sobre as relações trabalhistas, os quais estão detalhados no Quadro 1 abaixo.

Quadro 1: Retração das empresas do setor de transporte

\begin{tabular}{|l|}
\hline PRIMEIRA: RETRAÇÃO DAS EMPRESAS DO SETOR DE TRANSPORTE \\
\hline $85,3 \%$ das empresas transportadoras perceberam redução da demanda em março \\
\hline $82,5 \%$ esperava queda nos próximos 2 meses \\
\hline $\begin{array}{l}\text { 70,7\% enfrentavam problemas de caixa e comprometimento em realizar pagamentos: colaboradores e } \\
\text { fornecedores }\end{array}$ \\
\hline SEGUNDA: RELAÇÕES TRABALHISTAS \\
\hline $33 \%$ dos transportadores já realizaram demissões \\
\hline $18,1 \%$ pretendem realizar cortes \\
\hline $42,8 \%$ dos transportadores realizarem redução em seus quadros, até o final de maio
\end{tabular}

Fonte: Adaptado de CNT (2020)

Percebe-se que o setor de transporte tem enfrentado diversos desafios nesse cenário de pandemia do COVID-19 e muito tem sido feito para tentar minimizar esses impactos e garantir o abastecimento dos insumos mesmo em meio às políticas de isolamento. Quanto ao contexto do pós COVID-19, a maioria das consequências ainda são incertas e este momento deve ser visto como uma transformação para o setor de transporte, bem como as políticas que o regem. Desde que foram relatadas as informações sobre o COVID-19, várias reportagens sobre o impacto da pandemia na logística foram noticiadas. O Quadro 2 abaixo ilustra sobre algumas das principais noticias, as datas que foram expostas e um breve resumo do contexto.

Quadro 2: Principais notícias sobre os impactos do COVID-19 no Brasil e no Mundo

\begin{tabular}{|l|l|}
\hline \multicolumn{1}{|c|}{ FONTE } & \multicolumn{1}{c|}{ DESCRIÇÃO } \\
\hline $\begin{array}{l}\text { 24/03: Forbes - How the coronavirus will shape the } \\
\text { food supply chain }\end{array}$ & $\begin{array}{l}\text { Autor analisa como o supply chain está sendo impactado pela } \\
\text { pandemia, analisando as dificuldades das empresas de alimentos } \\
\text { com o novo cenário, a importância da mão de obra nesse período } \\
\text { e os problemas na previsão da demanda. }\end{array}$ \\
\hline $\begin{array}{l}\text { 05/04: World Economic Forum - 3 iniciativas que } \\
\text { executivos de Supply Chain podem implementar } \\
\text { para preparar a empresa para a realidade pós covid- } \\
19\end{array}$ & $\begin{array}{l}\text { O mundo mudou com a covid-19, e o primeiro impacto foi a } \\
\text { retração da economia e a perda de milhares de empregos. Uma } \\
\text { segunda onda está por vir, mas ainda não se sabe o impacto dela. } \\
2008 \text { foi o ano da crise econômica. 2020 é o ano da crise da } \\
\text { cadeia de suprimentos. }\end{array}$ \\
\hline
\end{tabular}




\begin{tabular}{|c|c|}
\hline $\begin{array}{l}\text { 07/04: MIT Technology Review - Pandemia } \\
\text { bagunçou a cadeia de suprimentos global. } \\
\text { Blockchain pode ajudar }\end{array}$ & $\begin{array}{l}\text { Registros do blockchain podem oferecer aos compradores uma } \\
\text { conexão mais resiliente com os seus fornecedores }\end{array}$ \\
\hline $\begin{array}{l}\text { 12/04: Forbes - Coronavírus deveria inspirar as } \\
\text { empresas a preparar a sua cadeia de suprimentos } \\
\text { para o futuro }\end{array}$ & $\begin{array}{l}\text { Segundo pesquisa recente, mais de } 30 \% \text { dos executivos de } \\
\text { finanças nos Estados Unidos e no México apontaram problemas } \\
\text { com a sua cadeia de suprimentos uma das suas três principais } \\
\text { preocupações em relação à pandemia do coronavírus. }\end{array}$ \\
\hline $\begin{array}{l}\text { 14/04: Globorural - Pandemia reduz transporte } \\
\text { rodoviário de cargas em } 43,9 \% \text { no Brasil, aponta } \\
\text { nova pesquisa }\end{array}$ & $\begin{array}{l}\text { Estudo da NTC\&Logística aponta para redução maior }(46,3 \%) \\
\text { no caso de cargas fracionadas no mesmo período. }\end{array}$ \\
\hline $\begin{array}{l}\text { 15/04: The Hill - Gestão da cadeia de suprimentos } \\
\text { é uma arma poderosa na guerra contra o coronavírus }\end{array}$ & $\begin{array}{l}\text { Embora seria muito custoso para as empresas estarem sempre } \\
\text { preparadas para eventos esporádicos, como a pandemia da covid- } \\
19 \text {, cadeias consideradas essenciais deveriam ter planos para esse } \\
\text { tipo de situação. }\end{array}$ \\
\hline $\begin{array}{l}\text { 24/04: Jornal do Comércio (RS) - Coronavírus e a } \\
\text { logística de entrega no Brasil }\end{array}$ & $\begin{array}{l}\text { Planejamento da demanda e gestão de armazenagem e das } \\
\text { entregas estão entre as atividades mais impactadas nesse período } \\
\text { de pandemia. }\end{array}$ \\
\hline $\begin{array}{l}\text { 21/04: Supply Chain } 247 \text { - Covid - } 19 \text { e cadeias de } \\
\text { suprimento despedaçadas }\end{array}$ & $\begin{array}{l}\text { Paper analisa como a covid-19 afetou as cadeias de suprimentos } \\
\text { e mostra como reduzir vulnerabilidade como uma cadeia mais } \\
\text { inteligente }\end{array}$ \\
\hline
\end{tabular}

Fonte: Lobo, 2020.

É sabido que o transporte possuía entraves mesmo antes da COVID-19, tendo alguns setores sido afetados, mas houve uma rapidez na adaptação no quadro de crise sanitária. Há empresas que não conseguiram se manter, mas as que conseguirem, tornar-se-ão melhores ao final de tudo isso.

\section{CONSIDERAÇÕES FINAIS}

Embora haja uma grande porcentagem da população em isolamento, há setores da economia que precisam funcionar e como forma de garantir que isso ocorra é necessário que exista condições para a realização da logística de transporte.

É cógnito que a pandemia ocasionou um grande impacto seja de âmbito econômico, político e/ou social, e também uma mudança abrupta nas rotinas. Assim, com esse cenário agora vivenciado, observa-se mais uma vez a importância do transporte na economia brasileira, visto que interferem diretamente no PIB nacional e como consequência, influenciará no desenvolvimento do país. Necessária tem sido a adaptação a demanda, que surgiram novas maneiras de gerir os diversos setores da economia a fim de garantir um melhor desempenho e atender as necessidades de forma eficiente e eficaz, levando em consideração o atual cenário.

Dessa forma, pode-se perceber que as organizações estão buscando um melhor planejamento a fim de se manter no mercado competidor e sobretudo cumprir com a missão da logística, ou 
seja, atender as necessidades do cliente ou servidor na hora certa, no lugar correto, com as devidas requisições e com o menor custo possível. Nesse contexto, a logística de transporte tem sido uma das principais atividades para que a dinâmica da sociedade ocorra mesmo com atribulações ocasionadas pela pandemia do COVID-19.

\section{REFERÊNCIAS BIBLIOGRÁFICAS}

ABROUG, F. et al. Family Cluster of Middle East Respiratory Syndrome Coronavirus Infections. Tunisia, 2013. Emerging Infectious Diseases, [S.l.], v. 20, n. 9, p. 1.527-1.530, september, 2014.

ANDRADE, Maria Margarida de. Introdução a Metodologia do Trabalho Científico. 10. ed. São Paulo: Atlas, 2017.

BALLOU, Ronald H. Gerenciamento da cadeia de suprimentos: planejamento, organização e logística empresarial. $4^{a}$ ed. Porto Alegre: Bookmann, 2001.

BRASIL. Ministério da Saúde. 2020. Disponível em: https://coronavirus.saude.gov.br/sobre-a-doenca\#o-que-ecovid. <ACESSO EM 21/04/2020 ÀS 17:48>

CAVANAGH, D. Coronavirus avian infectious bronchitis vírus. Veterinary Research, [S.l.], v. 38, n. 2, p. 281297, march-april, 2007.

Coronavírusírus: Infraestrutura estabelece malha logística para garantir abastecimento nacional. Gov.br, 2020. Disponível em: https://www.gov.br/pt-br/noticias/saude-e-vigilancia-sanitaria/2020/03/infraestruturaestabelece-malha-logistica-para-garantir-abastecimento-nacional. Acesso em: 14 mai. 2020.

COVID19: Painel Coronavírus. Coronavírus Brasil, 2020. Disponível em: https://covid.saude.gov.br/. Acesso em: 21 mai. 2020.

GUERESCHI, Jonathan Soares. Logística de transporte: a importância dos custos logisticos AJM Transporte LTDA / Jonathan Soares Guereschi. - Lins, 2012.

HOEK, L. V. D.; PYRC, K.; JEBBINK, M. Identification of a new human coronavirus. Nature Medicine, [S.l.], v. 10, p. 368-373, 2004.

JÚNIOR, J. H. S; Raasch, M; Soares, J. C; Ribeiro, L. V. H. A. S. Da Desinformação ao Caos: uma análise das Fake News frente à pandemia do Coronavírus (COVID-19) no Brasil. Cadernos de Prospecção - Salvador, v. 13, n. 2.

KÖCHE, José Carlos. Fundamentos de metodologia científica: Teoria da ciência e inicialização à pesquisa. Petrópolis, RJ: Vlozes, 2016. 185 p.

LOBO, Alexandre. Impactos do coronavírus na logística pelo mundo. Disponível em: <https://www.ilos.com.br/web/16-06-impactos-do-coronavirus-na-logistica-pelo-mundo/>. Acesso em: 22 abr. 2020

Logística de Transportes. Portogente, 2016. Disponível em: <https://portogente.com.br/portopedia/73441logistica-de-transportes.> Acesso em: 27 mai. 2020.

MOREIRA, Caio. Importância da logística. Portal dos administradores, Abril 2019. Disponível em: $<$ https://administradores.com.br/artigos/importancia-do-transporte-na-logistica〉. Acesso em: 25 mar. 2020.

NÓBREGA, Tiago. História da logística. Portal dos administradores, Dez 2010. Disponível em: <https://administradores.com.br/artigos/historia-da-logistica〉. Acesso em: 25 de mar. 2020.

O Transporte Move o Brasil. CNT Confederação Nacional de Transporte, 2019. Disponível em: <https://cnt.org.br/propostas-cnt-transporte.> Acesso em: 29 mai. 2020.

PAURA, Glávio Leal. Fundamentos da Logística. Curitiba, 2012. Rede e-Tec Brasil. 
PENNYCOOK, G.; RAND, D. G. Lazy, not biased: Susceptibility to partisan fake news is better explained by lack of reasoning than by motivated reasoning. Cognition, [S.l.], v. 188, p. 39-50, 2019.

PIB do transporte cai 2,4\% no primeiro trimestre de 2020. CNT Confederação Nacional de Transporte, 2020. Disponível em: <https://www.cnt.org.br/agencia-cnt/pib-do-transporte-cai-24-no-primeiro-trimestre-de-2020.> Acesso em: 29 mai. 2020.

PIRES, L. S. et al. O mapa do coronavírus: como aumentam os casos dia a dia no Brasil e no mundo. 2020. Disponível em:< https://brasil.elpais.com/brasil/2020/03/12/ciencia/1584026924_318538.html.> Acesso em: 21 abril de 2020 .

QUAMMEN, David. Spillover: Animal Infections and the Next Human Pandemic. Editora: W. W. Norton \& Company; Edição: Reprint (1 de outubro de 2012).

QUINTELLA, C. M; Quintella, H. M; Palma, G. B; Silva, S. C. R; Silva, G. H. R. Coronavírus (SARS-COV-2) e COVID-19: mapeamento de testes clínicos. Cadernos de Prospecção - Salvador, v. 13, n. 2, Edição Especial, p. 331-346, abril, 2020.

Setor de transporte encolhe 9\% em março. CNT Confederação Nacional de Transporte,2020. Disponível em: https://www.cnt.org.br/agencia-cnt/setor-de-transporte-encolhe-em-marco. Acesso em: 14 mai. 2020.

SPONCHIATO, Diogo. Coronavírus: como a pandemia nasceu de uma zoonose. 2020. Disponível em: <https://saude.abril.com.br/medicina/coronavirus-pandemia-zoonose/.> Acesso em: 21 abr. 2020.

ZIEBUHR, J. The Coronavirus Replicase. In: ENJUANES, L. (ed.). Coronavirus Replication and Reverse Genetics. Current Topics in Microbiology and Immunology. Berlin: Springer, 2005. v. 287. 